\title{
New Highly Efficient Families of Higher-Order Methods for Simple Roots, Permitting $f^{\prime}\left(x_{n}\right)=0$
}

\author{
Ramandeep Behl ${ }^{1}$ and V. Kanwar ${ }^{2}$ \\ ${ }^{1}$ School of Mathematics \& Computer Applications, Thapar University, Patiala 147 004, India \\ ${ }^{2}$ University Institute of Engineering and Technology, Panjab University, Chandigarh 160 014, India \\ Correspondence should be addressed to Ramandeep Behl; ramanbehl87@yahoo.in and V. Kanwar; vmithil@yahoo.co.in
}

Received 23 January 2014; Revised 18 March 2014; Accepted 19 March 2014; Published 5 May 2014

Academic Editor: Ram U. Verma

Copyright ( 2014 R. Behl and V. Kanwar. This is an open access article distributed under the Creative Commons Attribution License, which permits unrestricted use, distribution, and reproduction in any medium, provided the original work is properly cited.

\begin{abstract}
Construction of higher-order optimal and globally convergent methods for computing simple roots of nonlinear equations is an earliest and challenging problem in numerical analysis. Therefore, the aim of this paper is to present optimal and globally convergent families of King's method and Ostrowski's method having biquadratic and eight-order convergence, respectively, permitting $f^{\prime}(x)=$ 0 in the vicinity of the required root. Fourth-order King's family and Ostrowski's method can be seen as special cases of our proposed scheme. All the methods considered here are found to be more effective to the similar robust methods available in the literature. In their dynamical study, it has been observed that the proposed methods have equal or better stability and robustness as compared to the other methods.
\end{abstract}

\section{Introduction}

One topic which has always been of paramount importance in computational mathematics is that of approximating efficiently roots of equations of the form

$$
f(x)=0,
$$

where $f: D \subset \mathbb{R} \rightarrow \mathbb{R}$ is a nonlinear continuous function on $D$. The most famous one-point iterative method for solving preceding equation (1) is probably the quadratically convergent Newton's method given by

$$
x_{n+1}=x_{n}-\frac{f\left(x_{n}\right)}{f^{\prime}\left(x_{n}\right)} .
$$

However, a major difficulty in the application of Newton's method is the selection of initial guess such that neither the guess is far from zero nor the derivative is small in the vicinity of the required root; otherwise the method fails miserably. Finding a criterion for choosing initial guess is quite cumbersome and, therefore, more effective globally convergent algorithms are still needed. For resolving this problem, Kumar et al. [1] have proposed the following onepoint iterative scheme given by

$$
x_{n+1}=x_{n}-\frac{f\left(x_{n}\right)}{f^{\prime}\left(x_{n}\right)-\lambda_{1} f\left(x_{n}\right)} .
$$

This scheme is derived by implementing approximations through a straight line in the vicinity of required root. This family converges quadratically under the condition $f^{\prime}\left(x_{n}\right)-$ $\lambda_{1} f\left(x_{n}\right) \neq 0$, while $f^{\prime}\left(x_{n}\right)=0$ is permitted at some points. For $\lambda_{1}=0$, we obtain Newton's method. The error equation of scheme (3) is given by

$$
e_{n+1}=\left(\lambda_{1}-c_{2}\right) e_{n}^{2}+O\left(e_{n}^{3}\right),
$$

where $e_{n}=x_{n}-r, c_{k}=(1 / k !)\left(f^{(k)}(r) / f^{\prime}(r)\right), k=2,3, \ldots$, and $x=r$ is the root of nonlinear equation (1). In order to obtain quadratic convergence, the entity in the denominator should be the largest in magnitude. Further, it can be seen that this family of Newton's method gives very good approximation to the root when $\left|\lambda_{1}\right|$ is small. This is because, for small values of $\lambda_{1}$, slope or angle of inclination of straight line with $x$-axis becomes smaller; that is, as $\lambda_{1} \rightarrow 0$, the straight line tends to $x$-axis. 
Multipoint iterative methods can overcome theoretical limits of one-point methods concerning the convergence order and computational efficiency. Therefore, the convergence order and computational efficiency of the one-point iterative methods are lower than multipoint iterative methods. In recent years, many multipoint iterative methods have been proposed for solving nonlinear equations that improve local convergence order of the classical Newton method; see [1-17]. In 1973, King [2, 3] had proposed an optimal family of fourth-order multipoint methods requiring three functional evaluations per full iteration, which is given by

$$
\begin{gathered}
y_{n}=x_{n}-\frac{f\left(x_{n}\right)}{f^{\prime}\left(x_{n}\right)}, \\
x_{n+1}=x_{n}-\frac{f^{2}\left(x_{n}\right)+(\beta-1) f\left(x_{n}\right) f\left(y_{n}\right)+\beta f^{2}\left(y_{n}\right)}{f^{\prime}\left(x_{n}\right)\left[f\left(x_{n}\right)+(\beta-2) f\left(y_{n}\right)\right]},
\end{gathered}
$$

where $\beta \in \mathbb{R}$.

For $\beta=0$, one can easily get the well-known Ostrowski's method $[2,4,5]$. However, all these multipoint methods are the variants of Newton's method and the iteration can be aborted due to the overflow or leads to divergence, if the derivative of the function at an iterative point is singular or almost singular, which restrict their applications in practical.

Therefore, construction of an optimal class of King's method and Ostrowski's method having biquadratic and eighth-order convergence, respectively, and converge to the required root even though the guess is far from zero or the derivative is small in the vicinity of the required root is an open and challenging problem in computational mathematics. With this aim, we intend to propose an optimal scheme of King's family in which $f^{\prime}(x)=0$ is permitted at some points in the neighborhood of required root. All the proposed methods considered here are found to be effective and comparable to the classical Jarratt's method [7], Ostrowski's method, King's method, and recently published eighth-order methods, respectively.

\section{Development of Fourth-Order Optimal Methods}

In this section, we intend to develop new optimal families of King's type method and Ostrowski's type method, in which $f^{\prime}(x)=0$ is permitted at some points. For this purpose, we consider the following two-point scheme:

$$
\begin{gathered}
u_{n}=x_{n}-\frac{f\left(x_{n}\right)}{f^{\prime}\left(x_{n}\right)-\lambda_{1} f\left(x_{n}\right)}, \\
x_{n+1}=u_{n}-\frac{f\left(u_{n}\right)}{f^{\prime}\left(u_{n}\right)} .
\end{gathered}
$$

This method has biquadratic convergence and satisfies the following error equation:

$$
e_{n+1}=\left(\lambda_{1}-c_{2}\right)^{2} c_{2} e_{n}^{4}+O\left(e_{n}^{5}\right)
$$

But according to the Kung-Traub conjecture [8], the above method (6) is not an optimal method because it has fourthorder convergence and requires four functional evaluations per full iteration. However, we can reduce the number of function evaluations by using suitable approximation of $f^{\prime}\left(u_{n}\right)$. Therefore, we can approximate $f^{\prime}\left(u_{n}\right)$ by considering an approximation (similar to King's approximation [3]) given by

$$
f^{\prime}\left(u_{n}\right)=\left(\beta_{1} f^{\prime}(x)-\lambda_{1} f(x)\right)\left(\frac{f\left(x_{n}\right)+\beta_{2} f\left(u_{n}\right)}{\beta_{3} f\left(x_{n}\right)+\beta_{4} f\left(u_{n}\right)}\right),
$$

where $\beta_{1}, \beta_{2}, \beta_{3}$, and $\beta_{4}$ are four disposable parameters such that the order of convergence, that reaches at optimal level four without using any more functional evaluations. By using the above value of $f^{\prime}\left(u_{n}\right)$ in scheme (6), we get

$$
\begin{gathered}
u_{n}=x_{n}-\frac{f\left(x_{n}\right)}{f^{\prime}\left(x_{n}\right)-\lambda_{1} f\left(x_{n}\right)}, \\
x_{n+1}=u_{n}-\frac{f\left(u_{n}\right)}{\beta_{1} f^{\prime}(x)-\lambda_{1} f(x)}\left(\frac{\beta_{3} f\left(x_{n}\right)+\beta_{4} f\left(u_{n}\right)}{f\left(x_{n}\right)+\beta_{2} f\left(u_{n}\right)}\right) .
\end{gathered}
$$

Theorem 1 indicates that under what choices on the disposable parameters in (9), the order of convergence will reach at optimal level four.

\subsection{Order of Convergence}

Theorem 1. Let $f: I \subseteq \mathbb{R} \rightarrow \mathbb{R}$ have at least third-order continuous derivatives defined on an open interval I, enclosing a simple zero of $f(x)$ (say $x=r \in I)$. Assume that initial guess $x=x_{0}$ is sufficiently close to $r$ and $f^{\prime}\left(x_{n}\right)-\lambda_{1} f\left(x_{n}\right) \neq 0$ in $I$. Then the family of iterative methods defined by (9) has fourthorder convergence when

$$
\beta_{1}=\frac{1}{2}, \quad \beta_{3}=\frac{1}{2}, \quad \beta_{4}=\frac{\beta_{2}+2}{2},
$$

respectively. It satisfies the following error equation:

$$
\begin{aligned}
e_{n+1}=\left(c_{2}-\lambda_{1}\right)[ & 2\left(\beta_{2}+1\right) \lambda_{1}^{2}-\left(4 \beta_{2}+7\right) \lambda_{1} c_{2} \\
+ & \left.\left(2 \beta_{2}+5\right) c_{2}^{2}-c_{3}\right] e_{n}^{4}+O\left(e_{n}^{5}\right),
\end{aligned}
$$

where $e_{n}=x_{n}-r$ and $c_{k}$.

Proof. Let $x=r$ be a simple zero of $f(x)$. Expanding $f\left(x_{n}\right)$ and $f^{\prime}\left(x_{n}\right)$ about $x=r$ by Taylor's series expansion, we have

$$
\begin{gathered}
f\left(x_{n}\right)=f^{\prime}(r)\left(e_{n}+c_{2} e_{n}^{2}+c_{3} e_{n}^{3}+c_{4} e_{n}^{4}+c_{5} e_{n}^{5}+c_{6} e_{n}^{6}\right. \\
\left.+c_{7} e_{n}^{7}+c_{8} e_{n}^{8}\right)+O\left(e_{n}^{9}\right) \\
f^{\prime}\left(x_{n}\right)=f^{\prime}(r)\left(1+2 c_{2} e_{n}+3 c_{3} e_{n}^{2}+4 c_{4} e_{n}^{3}+5 c_{5} e_{n}^{4}+6 c_{6} e_{n}^{5}\right. \\
\left.+7 c_{7} e_{n}^{6}+8 c_{8} e_{n}^{7}+9 c_{9} e_{n}^{8}\right)+O\left(e_{n}^{9}\right)
\end{gathered}
$$

respectively. 
From (12), we have

$$
\begin{aligned}
& \frac{f\left(x_{n}\right)}{f^{\prime}\left(x_{n}\right)-\lambda_{1} f\left(x_{n}\right)} \\
& =e_{n}+\left(\lambda_{1}-c_{2}\right) e_{n}^{2}+\left(\lambda_{1}^{2}-2 \lambda_{1} c_{2}+2 c_{2}^{2}-2 c_{3}\right) e_{n}^{3} \\
& \quad+\left(\lambda_{1}^{3}+5 \lambda_{1} c_{2}^{2}-4 c_{2}^{3}-4 \lambda_{1} c_{3}+c_{2}\left(7 c_{3}-3 \lambda_{1}^{2}\right)-3 c_{4}\right) e_{n}^{4} \\
& \quad+O\left(e_{n}^{5}\right),
\end{aligned}
$$

and in the combination of Taylor series expansion of $f\left(x_{n}-\right.$ $\left.\left(f\left(x_{n}\right) /\left(f^{\prime}\left(x_{n}\right)-\lambda_{1} f\left(x_{n}\right)\right)\right)\right)$ about $x=r$, we get

$$
\begin{aligned}
& f\left(u_{n}\right)=f\left(x_{n}-\right.\left.\frac{f\left(x_{n}\right)}{f^{\prime}\left(x_{n}\right)-\lambda_{1} f\left(x_{n}\right)}\right) \\
&=f^{\prime}(r)\left[\left(c_{2}-\lambda_{1}\right) e_{n}^{2}-\left(\lambda_{1}^{2}-2 \lambda_{1} c_{2}+2 c_{2}^{2}-2 c_{3}\right) e_{n}^{3}\right. \\
&-\left(\lambda_{1}^{3}+7 \lambda_{1} c_{2}^{2}-5 c_{2}^{3}-4 \lambda_{1} c_{3}\right. \\
&\left.\left.-c_{2}\left(4 \lambda_{1}^{2}-7 c_{3}\right)-3 c_{4}\right) e_{n}^{4}\right]+O\left(e_{n}^{5}\right) .
\end{aligned}
$$

Furthermore, we obtain

$$
\begin{aligned}
& \frac{f\left(u_{n}\right)\left(\beta_{3} f\left(x_{n}\right)+\beta_{4} f\left(u_{n}\right)\right)}{\left(\beta_{1} f^{\prime}(x)-\lambda_{1} f(x)\right) f\left(x_{n}\right)+\beta_{2} f\left(u_{n}\right)} \\
& =\left(\frac{\beta_{3}\left(c_{2}-\lambda_{1}\right)}{\beta_{1}}\right) e_{n}^{2}+A_{4} e_{n}^{3}+A_{5} e_{n}^{4}+O\left(e_{n}^{5}\right),
\end{aligned}
$$

where

$$
\begin{aligned}
& A_{4}=\frac{1}{\beta_{1}^{2}}[ \lambda_{1}^{2}\left(\beta_{3}+\left(\beta_{3}-\beta_{4}+\beta_{2} \beta_{3}\right) \beta_{1}\right) \\
&+ \lambda_{1}\left(\beta_{3}+\left(4 \beta_{3}-2 \beta_{4}+2 \beta_{2} \beta_{3}\right) \beta_{1}\right) c_{2} \\
&+\left.\left(\beta_{4}-\left(\beta_{2}+4\right) \beta_{3}\right) \beta_{1} c_{2}^{2}+2 \beta_{1} \beta_{3} c_{3}\right], \\
& A_{5}=\frac{\lambda_{1} \beta_{1}}{\beta_{1}^{3}}[-\beta_{3}\left(\beta_{2}+15 \beta_{1}+14 \beta_{1} \beta_{2}+3 \beta_{1} \beta_{2}^{2}+5\right) \\
&+ \beta_{4}\left(1+\left(3 \beta_{2}+14\right) \beta_{1}\right) c_{2}^{2} \\
&+\left(\left(\beta_{2}^{2}+7 \beta_{2}+13\right) \beta_{3}-\left(\beta_{2}-7\right) \beta_{4}\right) \beta_{1}^{2} c_{2}^{3} \\
&+ c_{2}\left(\lambda _ { 1 } ^ { 2 } \left(-\beta_{1} \beta_{4}\left(2+3\left(\beta_{2}+3\right) \beta_{1}\right)\right.\right. \\
&+\beta_{3}\left(1+\left(2 \beta_{2}+5\right) \beta_{1}\right. \\
&\left.\left.+3\left(\beta_{2}^{2}+3 \beta_{2}+2\right) \beta_{1}^{2}\right)\right) \\
&\left.+2\left(2 \beta_{4}-\left(2 \beta_{2}+7\right) \beta_{3}\right) \beta_{1}^{2} c_{3}\right) \\
&\left.-\beta_{1}\left(-4 \beta_{1} \beta_{4}+\beta_{3}\left(4 \beta_{1} \beta_{2}+7 \beta_{1}+2\right)\right) c_{3}\right] .
\end{aligned}
$$

Using (13), (14), and (15) in scheme (9), we have the following error equation:

$$
\begin{aligned}
e_{n+1}= & e_{n}-\frac{f\left(x_{n}\right)}{f^{\prime}\left(x_{n}\right)-\lambda_{1} f\left(x_{n}\right)} \\
& -\frac{f\left(u_{n}\right)\left(\beta_{3} f\left(x_{n}\right)+\beta_{4} f\left(u_{n}\right)\right)}{\left(\beta_{1} f^{\prime}(x)-\lambda_{1} f(x)\right) f\left(x_{n}\right)+\beta_{2} f\left(u_{n}\right)} \\
= & \left(\frac{\left(\beta_{3}-\beta_{1}\right)\left(\lambda_{1}-c_{2}\right)}{\beta_{1}}\right) e_{n}^{2} \\
& +\frac{1}{\beta_{1}^{2}}\left[\lambda_{1}^{2}\left(-\beta_{1}\left(\beta_{1}+\beta_{4}\right)+\beta_{3}\left(\beta_{1} \beta_{2}+\beta_{1}+1\right)\right)\right. \\
& -\lambda_{1}\left(-2 \beta_{1}\left(\beta_{1}+\beta_{4}\right)+\beta_{3}\left(2\left(\beta_{2}+2\right) \beta_{1}+1\right)\right) \\
& \times c_{2}+\left(-\beta_{4}+\left(\beta_{2}+4\right) \beta_{3}-2 \beta_{1}\right) \beta_{1} c_{2}^{2} \\
& \left.+2 \beta_{1}\left(\beta_{1}-\beta_{3}\right) c_{3}\right] e_{n}^{3}+O\left(e_{n}^{4}\right) .
\end{aligned}
$$

For obtaining an optimal general class of fourth-order iterative methods, the coefficients of $e_{n}^{2}$ and $e_{n}^{3}$ in error equation (17) must be zero simultaneously. Therefore, from (17), we have the following equations involving of $\beta_{1}, \beta_{2}, \beta_{3}$, and $\beta_{4}$ as follows:

$$
\begin{gathered}
\left(\beta_{3}-\beta_{1}\right)=0, \\
-\beta_{1}\left(\beta_{1}+\beta_{4}\right)+\beta_{3}\left(\beta_{1} \beta_{2}+\beta_{1}+1\right)=0, \\
-\lambda_{1}\left(-2 \beta_{1}\left(\beta_{1}+\beta_{4}\right)+\beta_{3}\left(2\left(\beta_{2}+2\right) \beta_{1}+1\right)\right)=0, \\
\left(-\beta_{4}+\left(\beta_{2}+4\right) \beta_{3}-2 \beta_{1}\right)=0,
\end{gathered}
$$

respectively.

After simplifying (18), we get

$$
\beta_{1}=\frac{1}{2}, \quad \beta_{3}=\frac{1}{2}, \quad \beta_{4}=\frac{\beta_{2}+2}{2},
$$

respectively.

Using these values of $\beta_{1}, \beta_{3}$, and $\beta_{4}$ in scheme (9), we will get the following error equation:

$$
\begin{aligned}
e_{n+1}=\left(c_{2}-\lambda_{1}\right)[ & {\left[2\left(\beta_{2}+1\right) \lambda_{1}^{2}-\left(4 \beta_{2}+7\right) \lambda_{1} c_{2}\right.} \\
+ & \left.\left(2 \beta_{2}+5\right) c_{2}^{2}-c_{3}\right] e_{n}^{4}+O\left(e_{n}^{5}\right),
\end{aligned}
$$

where $\lambda_{1}, \beta_{2} \in \mathbb{R}$ are two free disposable parameters.

This reveals that the general two-step class of King's type family (9) reaches the optimal order of convergence four by using only three functional evaluations per full iteration. This class of King's method will converge to the required root even if $f^{\prime}(x)=0$, unlike King's family. This completes the proof of Theorem 1 . 
2.2. Some Special Cases. Finally, by using specific values of $\beta_{1}, \beta_{3}$, and $\beta_{4}$, which are defined in Theorem 1 , we get the following general class of King's type method given by

$$
\begin{gathered}
u_{n}=x_{n}-\frac{f\left(x_{n}\right)}{f^{\prime}\left(x_{n}\right)-\lambda_{1} f\left(x_{n}\right)}, \\
x_{n+1}=u_{n}-\frac{f\left(u_{n}\right)\left(f\left(x_{n}\right)+\left(\beta_{2}+2\right) f\left(u_{n}\right)\right)}{\left(f^{\prime}\left(x_{n}\right)-2 \lambda_{1} f\left(x_{n}\right)\right)\left(f\left(x_{n}\right)+\beta_{2} f\left(u_{n}\right)\right)},
\end{gathered}
$$

where $\lambda_{1}, \beta_{2} \in \mathbb{R}$ are two free disposable parameters. Again in (21), $\lambda_{1}$ is chosen as a positive or negative sign so as to make the denominator the largest in magnitude. Now, we will consider some particular cases of the proposed scheme (21) depending upon $\beta_{2}$ and $\lambda_{1}$ as follows:

For $\beta_{2}=\gamma-2$, family (21) reads as

$$
u_{n}=x_{n}-\frac{f\left(x_{n}\right)}{f^{\prime}\left(x_{n}\right)-\lambda_{1} f\left(x_{n}\right)} \text {, }
$$

$$
\begin{aligned}
& x_{n+1} \\
& \quad=u_{n}-\frac{f\left(u_{n}\right)\left(f\left(x_{n}\right)+\gamma f\left(u_{n}\right)\right)}{\left(f\left(x_{n}\right)+(\gamma-2) f\left(u_{n}\right)\right)\left(f^{\prime}\left(x_{n}\right)-2 \lambda_{1} f\left(x_{n}\right)\right)} .
\end{aligned}
$$

This is a new modified family of King's type method. For $\lambda_{1}=$ 0 , we recover the well-known King's family [3]. Further, we can easily get many other new optimal families of methods by choosing the different values of disposable parameters $\lambda_{1}$ and $\gamma$ as follows.

For $\gamma=0$, family (22) reads as

$$
\begin{gathered}
u_{n}=x_{n}-\frac{f\left(x_{n}\right)}{f^{\prime}\left(x_{n}\right)-\lambda_{1} f\left(x_{n}\right)}, \\
x_{n+1}=u_{n}-\frac{f\left(x_{n}\right) f\left(u_{n}\right)}{\left(f\left(x_{n}\right)-2 f\left(u_{n}\right)\right)\left(f^{\prime}\left(x_{n}\right)-2 \lambda_{1} f\left(x_{n}\right)\right)} .
\end{gathered}
$$

This is a new modified optimal family of fourth-order Ostrowski's type method. For $\lambda_{1}=0$, scheme (23) reduces the well-known Ostrowski's method $[4,5]$.

In order to overcome this problem, some attempts have been made by Kanwar and Tomar [6] to develop an optimal family of Ostrowski's method. They obtained a third-order multipoint family of Ostrowski's method in which $f^{\prime}(x)=0$ is permitted at some points and did not get success in this direction. Therefore, we do not have any optimal family of fourth-order or eighth-order Ostrowski's method or King's methods, respectively, in which $f^{\prime}(x)=0$ is permitted at some points.

\section{Three-Point Families of King's and Ostrowski's Type Methods}

In this section, we want to extend the family of King's type methods (22) up to eight-order convergence. Therefore, we consider the following three-point scheme:

$$
\begin{gathered}
u_{n}=x_{n}-\frac{f\left(x_{n}\right)}{f^{\prime}\left(x_{n}\right)-\lambda_{1} f\left(x_{n}\right)}, \\
z_{n}=u_{n}-\frac{f\left(u_{n}\right)\left(f\left(x_{n}\right)+\gamma f\left(u_{n}\right)\right)}{\left(f^{\prime}\left(x_{n}\right)-2 \lambda_{1} f\left(x_{n}\right)\right)\left(f\left(x_{n}\right)+(\gamma-2) f\left(u_{n}\right)\right)}, \\
x_{n+1}=z_{n}-\frac{f\left(z_{n}\right)}{f^{\prime}\left(z_{n}\right)} .
\end{gathered}
$$

This family has eight-order convergence and satisfies the following error equation:

$$
\begin{array}{r}
e_{n+1}=\left(\lambda_{1}-c_{2}\right)^{2} c_{2}\left(2(-1+\gamma) \lambda_{1}^{2}+\left(\lambda_{1}-4 \gamma \lambda_{1}\right) c_{2}\right. \\
\left.+(1+2 \gamma) c_{2}^{2}-c_{3}\right)^{2} e_{n}^{8}+O\left(e_{n}^{9}\right) .
\end{array}
$$

But according to the Kung-Traub conjecture [8], the above family of methods (24) is not an optimal family because it has eight-order convergence and requires five functional evaluations per full iteration. However, we can reduce the number of function evaluations by using some suitable approximation of $f^{\prime}\left(z_{n}\right)$. Here, we approximate $f^{\prime}(z)$ by Hermite interpolation of degree three such that $H_{3}\left(x_{n}\right)=$ $f\left(x_{n}\right), H_{3}\left(u_{n}\right)=f\left(u_{n}\right), H_{3}\left(z_{n}\right)=f\left(z_{n}\right)$ and $H_{3}^{\prime}\left(x_{n}\right)=f^{\prime}\left(x_{n}\right)$; we derive

$$
\begin{aligned}
f(x) \approx & H_{3}(x) \\
= & f\left(z_{n}\right)+f\left[z_{n}, u_{n}\right]\left(x-z_{n}\right) \\
& +f\left[z_{n}, u_{n}, x_{n}\right]\left(x-z_{n}\right)\left(x-u_{n}\right) \\
& +f\left[z_{n}, u_{n}, x_{n}, x_{n}\right]\left(x-z_{n}\right)\left(x-u_{n}\right)\left(x-x_{n}\right) ;
\end{aligned}
$$

then we have

$$
\begin{aligned}
f^{\prime}\left(z_{n}\right) \approx H_{3}^{\prime}(x)= & f\left[z_{n}, u_{n}\right]+f\left[z_{n}, u_{n}, x_{n}\right]\left(z_{n}-u_{n}\right) \\
& +f\left[z_{n}, u_{n}, x_{n}, x_{n}\right]\left(z_{n}-u_{n}\right)\left(z_{n}-x_{n}\right) .
\end{aligned}
$$


Therefore, our modified optimal eight-order King's family (24) is obtained as follows:

$$
\begin{aligned}
& u_{n}=x_{n}-\frac{f\left(x_{n}\right)}{f^{\prime}\left(x_{n}\right)-\lambda_{1} f\left(x_{n}\right)}, \\
& z_{n}=u_{n}-\frac{f\left(u_{n}\right)\left(f\left(x_{n}\right)+\gamma f\left(u_{n}\right)\right)}{\left(f^{\prime}\left(x_{n}\right)-2 \lambda_{1} f\left(x_{n}\right)\right)\left(f\left(x_{n}\right)+(\gamma-2) f\left(u_{n}\right)\right)}, \\
& x_{n+1}=z_{n}-\left(f\left(z_{n}\right) \times\left(f\left[z_{n}, u_{n}\right]+f\left[z_{n}, u_{n}, x_{n}\right]\left(z_{n}-u_{n}\right)\right.\right. \\
& +f\left[z_{n}, u_{n}, x_{n}, x_{n}\right] \\
& \left.\left.\times\left(z_{n}-u_{n}\right)\left(z_{n}-x_{n}\right)\right)^{-1}\right) \text {. }
\end{aligned}
$$

Theorem 2 indicates that under what choices on the disposable parameters in (28), the order of convergence will reach at the optimal level eight.

Theorem 2. If $f: I \subseteq \mathbb{R} \rightarrow \mathbb{R}$ is sufficiently differentiable function defined on an open interval $I$, enclosing a simple zero of $f(x)$ (say $x=r \in I$ ), assume that initial guess $x=x_{0}$ is sufficiently close to $r$ and $f^{\prime}\left(x_{n}\right)-\lambda_{1} f\left(x_{n}\right) \neq 0$ in I. Then the modified King's family defined by (28) has order of convergence eight and satisfies the following error equation:

$$
\begin{aligned}
e_{n+1}=[ & \left(\lambda_{1}-c_{2}\right)^{2} \\
& \times\left(2 \lambda_{1}^{2}(\gamma-1)-\lambda_{1}(4 \gamma-1) c_{2}+(2 \gamma+1) c_{2}^{2}-c_{3}\right) \\
& \times\left(-\lambda_{1}(4 \gamma-1) c_{2}^{2}+(2 \gamma+1) c_{2}^{3}\right. \\
& \left.\left.+c_{2}\left(2 \lambda_{1}^{2}(\gamma-1)-c_{3}\right)+c_{4}\right)\right] e_{n}^{8}+O\left(e_{n}^{9}\right)
\end{aligned}
$$

Proof. The proof of this theorem is omitted here because it is quite lengthy. Therefore, we have given its Mathematica program code in the below mentioned program.

Using the Taylor series and symbolic computation in the programming package Wolfram Mathematica 9, we can find the order of convergence and the asymptotic error constant of the three-step methods (28). For simplicity, we sometimes omit the iteration index $n$ and write $e$ instead of $e_{n}$. The approximation $x_{n+1}$ to the root $r$ will be denoted by $x$. Regarding (28), let us introduce the following abbreviations used in the program:

$$
\begin{gathered}
e=x-r, \quad f x=f^{\prime}\left(x_{n}\right), \quad d f x=f^{\prime}\left(x_{n}\right), \\
c_{n}=\frac{f^{n}(r)}{n ! f^{\prime}(r)}, \quad f u=f\left(u_{n}\right), \quad f 1 d=f^{\prime}(r), \\
f z=f\left(z_{n}\right), \quad f x u=f\left[x_{n}, u_{n}\right], \quad f u z=f\left[u_{n}, z_{n}\right], \\
f x z=f\left[x_{n}, z_{n}\right], \quad f u x x=f\left[u_{n}, x_{n}, x_{n}\right], \\
f z u x=f\left[z_{n}, u_{n}, x_{n}\right], \quad f z x x x=f\left[z_{n}, x_{n}, x_{n}\right], \\
f z u x x=f\left[z_{n}, u_{n}, x_{n}, x_{n}\right] .
\end{gathered}
$$

Program code of the family (28) (written in Mathematica 9) is as follows:

$\operatorname{In}[1]: \quad f x=f 1 d *\left(e+c_{2} * e^{2}+c_{3} * e^{3}+c_{4} * e^{4}+c_{5} * e^{5}\right.$

$$
\left.+c_{6} * e^{6}+c_{7} * e^{7}+c_{8} * e^{8}\right)
$$

In [2]: $d f x=f 1 d *\left(1+2 e * c_{2}+3 e^{2} * c_{3}+4 e^{3} * c_{4}+5 e^{4}\right.$

$$
\left.* c_{5}+6 e^{5} * c_{6}+7 e^{6} * c_{7}+8 e^{7} * c_{8}\right)
$$

In [3]: $v 1=$ Series $\left[\frac{f x}{\left(d f x-\lambda_{1} * f x\right)},\{e, 0,8\}\right]$;

In [4]: $u=e-v 1$;

In [5]: $f u=f 1 d *\left(u+c_{2} * u^{2}+c_{3} * u^{3}+c_{4} * u^{4}+c_{5}\right.$

$$
\left.* u^{5}+c_{6} * u^{6}+c_{7} * u^{7}+c_{8} * u^{8}\right)
$$

In [6]: $z 1=f u *(f x+\gamma f u)$;

In [7]: $z 2=\left(d f x-2 * \lambda_{1} * f x\right) *(f x+(\gamma-2) * f u)$;

In [8]: $z 3=$ Series $\left[\frac{z 1}{z 2},\{e, 0,8\}\right] / /$ Simplify;

In [9]: $z=u-z 3 / /$ Simplify

In [10]: $f z=f 1 d *\left(z+c_{2} * z^{2}+c_{3} * z^{3}+c_{4} * z^{4}+c_{5}\right.$

$$
\left.* z^{5}+c_{6} * z^{6}+c_{7} * z^{7}+c_{8} * z^{8}\right)
$$

In [11]: $f x y=$ Series $\left[\frac{(f u-f x)}{(u-e)},\{e, 0,8\}\right]$;

In [12]: $f y z=$ Series $\left[\frac{(f u-f z)}{(u-z)},\{e, 0,8\}\right]$; 
In [13]: $f x z=$ Series $\left[\frac{(f x-f z)}{(e-z)},\{e, 0,8\}\right]$;

In [14]: $f y x x=$ Series $\left[\frac{(d f x-f x u)}{(e-u)},\{e, 0,8\}\right]$;

In [15]: $f z x x=$ Series $\left[\frac{(d f x-f x z)}{(e-z)},\{e, 0,8\}\right]$;

In [16]: $f z y x x=$ Series $\left[\frac{(f z x x-f u x x)}{(z-u)},\{e, 0,8\}\right]$;

In [17]: $f z y x=$ Series $\left[\frac{(f x z-f u z)}{(e-u)},\{e, 0,8\}\right]$;

In [18]: $e 1=$ Series $[z-(f z \times(f y z+f z y x *(z-y)$

$$
\begin{aligned}
& +f z y x x \\
& \left.*(z-e) *(z-y))^{-1}\right),
\end{aligned}
$$$$
\{e, 0,8\}]
$$

Out [9]: $z=\left(c_{2}-\lambda_{1}\right)\left[2\left(\beta_{2}+1\right) \lambda_{1}^{2}-\left(4 \beta_{2}+7\right) \lambda_{1} c_{2}\right.$

$$
\left.+\left(2 \beta_{2}+5\right) c_{2}^{2}-c_{3}\right] e^{4}+O\left(e^{5}\right),
$$

Out [18]: $e 1=\left(\lambda_{1}-c_{2}\right)^{2}\left(2 \lambda_{1}^{2}(\gamma-1)-\lambda_{1}(4 \gamma-1) c_{2}\right.$

$$
\begin{gathered}
\left.+(2 \gamma+1) c_{2}^{2}-c_{3}\right) \\
\times\left(-\lambda_{1}(4 \gamma-1) c_{2}^{2}+(2 \gamma+1) c_{2}^{3}\right. \\
\left.+c_{2}\left(2 \lambda_{1}^{2}(\gamma-1)-c_{3}\right)+c_{4}\right) e^{8}+O\left(e^{9}\right) .
\end{gathered}
$$

3.1. Special Cases. In this section, we will discuss some special cases of eight-order family of methods (28) as follows.

For $\gamma=1$, family (28) reads as

$$
\begin{aligned}
& u_{n}=x_{n}-\frac{f\left(x_{n}\right)}{f^{\prime}\left(x_{n}\right)-\lambda_{1} f\left(x_{n}\right)} \text {, } \\
& z_{n}=u_{n}-\frac{f\left(u_{n}\right)\left(f\left(x_{n}\right)+f\left(u_{n}\right)\right)}{\left(f^{\prime}\left(x_{n}\right)-2 \lambda_{1} f\left(x_{n}\right)\right)\left(f\left(x_{n}\right)-f\left(u_{n}\right)\right)} \text {, } \\
& x_{n+1}=z_{n}-\left(f\left(z_{n}\right) \times\left(f\left[z_{n}, u_{n}\right]+f\left[z_{n}, u_{n}, x_{n}\right]\left(z_{n}-u_{n}\right)\right.\right. \\
& +f\left[z_{n}, u_{n}, x_{n}, x_{n}\right] \\
& \left.\left.\times\left(z_{n}-u_{n}\right)\left(z_{n}-x_{n}\right)\right)^{-1}\right) \text {. }
\end{aligned}
$$

This is a new modified optimal eight-order family of King's type method.

$$
\text { For } \gamma=0 \text {, family (32) reads as }
$$

$$
\begin{aligned}
& u_{n}=x_{n}-\frac{f\left(x_{n}\right)}{f^{\prime}\left(x_{n}\right)-\lambda_{1} f\left(x_{n}\right)}, \\
& z_{n}=u_{n}-\frac{f\left(x_{n}\right) f\left(u_{n}\right)}{\left(f^{\prime}\left(x_{n}\right)-2 \lambda_{1} f\left(x_{n}\right)\right)\left(f\left(x_{n}\right)-2 f\left(u_{n}\right)\right)}, \\
& x_{n+1}=z_{n}-\left(f\left(z_{n}\right) \times\left(f\left[z_{n}, u_{n}\right]+f\left[z_{n}, u_{n}, x_{n}\right]\left(z_{n}-u_{n}\right)\right.\right. \\
& +f\left[z_{n}, u_{n}, x_{n}, x_{n}\right] \\
& \left.\left.\times\left(z_{n}-u_{n}\right)\left(z_{n}-x_{n}\right)\right)^{-1}\right) \text {. }
\end{aligned}
$$

This is a new modified optimal eight-order family of Ostrowski's type method.

\section{Numerical Experiments}

In this section, we will check the effectiveness of newly proposed optimal methods. We employ the present methods, namely, modified fourth-order family of King's method (22), for $\left(\gamma=1,\left|\lambda_{1}\right|=1 / 2\right)\left(\mathrm{MKM}_{4}\right)$, modified fourth-order family of Ostrowski's method (23), for $\left(\left|\lambda_{1}\right|=1 / 2\right)\left(\mathrm{MOM}_{4}^{1}\right)$, modified eight-order family of King's method (32), for $\left(\left|\lambda_{1}\right|=1 / 2\right)\left(\mathrm{MKM}_{8}\right)$, and modified eight-order family of Ostrowski's method (33), for $\left(\left|\lambda_{1}\right|=1 / 2\right)\left(\mathrm{MOM}_{8}\right)$, respectively, to solve nonlinear equations. These newly proposed methods were compared with the existing methods, namely, Jarratt's method $\left(\mathrm{JM}_{4}\right)$, King's method for $\gamma=1\left(\mathrm{KM}_{4}\right)$, Ostrowski's method $\left(\mathrm{OM}_{4}\right)$, Chun's method (21) $\left(\mathrm{CM}_{4}^{1}\right)$ and method (22) $\left(\mathrm{CM}_{4}^{2}\right)$ [9], Liu and Wang's method (18) for $(\alpha=$ $0, \beta=0)$ [14] $\left(\mathrm{LW}_{8}\right)$, Thukral's method (17) [15] $\left(\mathrm{TM}_{8}\right)$, Sharma and Sharma's method (5.1) for $(\alpha=1)$ [13] $\left(\mathrm{SS}_{8}\right)$, Kou and Wang's method (26) [12] $\left(\mathrm{KW}_{8}\right)$, and the Soleymani et al. method (16) for $(\alpha=3)$ [10] $\left(\mathrm{SM}_{8}\right)$, respectively. For better comparisons of our proposed methods, we have given two comparison tables in each example: one is corresponding to absolute error value of given nonlinear functions (with the same total number of functional evaluations =12) and the other is with respect to number of iterations taken by each method to obtain the root correct up to 35 significant digits. All computations have been performed using the programming package Mathematica 9 with multiple precision arithmetics. Here, the stopping criterion is described as the distance between two consecutive approximations for the required root that is less than the precision of $10^{-34}$. In the implementation of iterative methods, the good choice of initial guess is very important for all the variants of Newton's 
method; otherwise, convergence is not guaranteed. However, newly proposed families of methods, namely, (22), (23), (32), and (33), will converge to zero even though the guess is far away from the required root. Also, it can be observed from Tables $1,2,3,4,5,6,7$, and 8 that, in majority of the problems tested here, our proposed methods are efficient and show better performance than other existing methods.

Example $1(\sin x=0)$. This equation has an infinite number of roots but our desired root is $r=0$, which is correct up to 35 digits. It can be seen that Newton's method and its variants do not necessarily converge to the root that is nearest to the starting value. For example, $\mathrm{JM}_{4}, \mathrm{KM}_{4}, \mathrm{CM}_{4}^{1}, \mathrm{CM}_{4}^{2}$, $\mathrm{OM}_{4}, \mathrm{LW}_{8}$ (for $\alpha=0$ and $\beta=0$ ), $\mathrm{TM}_{8}, \mathrm{SS}_{8}($ for $\alpha=1$ ), $\mathrm{KW}_{8}$ (for $\alpha=3$ ), and $\mathrm{SM}_{8}$ with initial guess $x_{0}=-1.51$ converge to $6.2 \ldots, 12.5 \ldots, 8.4 \ldots,-9.4 \ldots, 9.4 \ldots, 31.4 \ldots$, $6.2 \ldots, 25.1 \ldots, 15.7 \ldots$, and $6788.9 \ldots$, respectively. Similarly, the above mentioned methods with initial guess $x_{0}=$ 1.51 converge to $-6.2 \ldots,-12.5 \ldots,-8.4 \ldots, 9.4 \ldots,-9.4 \ldots$, $-31.4 \ldots,-6.2 \ldots,-25.3 \ldots,-15.7 \ldots, 6757.5 \ldots$, respectively, and so on. However, newly proposed families of methods, namely, (22), (23), (32), and (33), do not exhibit this type of behavior.

Example $2\left(x e^{-x}+\sin x=0\right)$. This equation has an infinite number of roots but our desired root is $r=3.1 \ldots$. It can be seen that Newton's method and its variants do not necessarily converge to the root that is nearest to the starting value. For example, $\mathrm{JM}_{4}, \mathrm{KM}_{4}, \mathrm{CM}_{4}^{2}, \mathrm{OM}_{4}, \mathrm{LW}_{8}$ (for $\alpha=$ 0 and $\beta=0$ ), $\mathrm{TM}_{8}, \mathrm{SS}_{8}$ (for $\alpha=1$ ), $\mathrm{KW}_{8}($ for $\alpha=3$ ), and $\mathrm{SM}_{8}$ with initial guess $x_{0}=1.4$ converge to $9.4 \ldots$, $15.7 \ldots, 12.5 \ldots, 12.5 \ldots, 12.5 \ldots, 9.4 \ldots, 12.5 \ldots, 12.5 \ldots$, and $6.2 \ldots$, while $\mathrm{CM}_{4}^{1}$ converge to the desired root after finite number of iterations. Similarly, $\mathrm{JM}_{4}, \mathrm{KM}_{4}, \mathrm{CM}_{4}^{1}, \mathrm{CM}_{4}^{2}, \mathrm{OM}_{4}$, $\mathrm{SS}_{8}$ (for $\alpha=1$ ), $\mathrm{KW}_{8}$ (for $\alpha=3$ ), and $\mathrm{SM}_{8}$ with initial guess $x_{0}=1.5$ converge to $6.2 \ldots, 9.4 \ldots, 9.4 \ldots, 197.9 \ldots, 9.4 \ldots$, $9.4 \ldots, 9.4 \ldots$, and $9.4 \ldots$, respectively, while $\mathrm{LW}_{8}$ (for $\alpha=$ 0 and $\beta=0)$ and $\mathrm{TM}_{8}$ converge to the desired root. However, newly proposed families of methods, namely, (22), (23), (32), and (33), do not exhibit this type of behavior.

Example $3\left(x e^{-x}=0\right)$. Clearly, this equation has a root $r=$ 0 .... which is correct up to 35 digits. Care must be taken when applying either method for approximating the root. For any initial guess $x_{0}<0$, all the mentioned methods converge to the root very efficiently. But for initial guess $x_{0}>0$, only some of the methods converge to the required root. For example, $\mathrm{CM}_{4}^{2}, \mathrm{SS}_{8}$ (for $\alpha=1$ ), and $\mathrm{KW}_{8}$ (for $\alpha=3$ ), with initial guess $x_{0}=0.9$, converge to $33215.7 \ldots, 64.357 .8 \ldots$, and 291573.3 ..., while $\mathrm{KM}_{4}, \mathrm{LW}_{8}$ (for $\alpha=0$ and $\beta=0$ ), $\mathrm{TM}_{8}$, and $\mathrm{SM}_{8}$ diverge to the root. Further, the derivative of the function $x e^{-x}$ is zero at $x=1$. Therefore, all the variants of Newton's method fail with initial guess $x_{0}=1$. However, newly proposed families of methods, namely, (22), (23), (32), and (33), do not exhibit this type of behavior.
Example $4\left(x e^{-x^{2}}-\sin x^{2}+3 \cos x+5=0\right)$. This equation has finite number of roots but our desired root is $r=1.3 \ldots$ which is correct up to 35 digits. It can be seen that $\mathrm{KM}_{4}, \mathrm{CM}_{4}^{1}$, $\mathrm{CM}_{4}^{2}, \mathrm{LW}_{8}$ (for $\alpha=0$ and $\beta=0$ ), $\mathrm{TM}_{8}, \mathrm{SS}_{8}$ (for $\alpha=1$ ), $\mathrm{KW}_{8}$ (for $\alpha=3$ ), and $\mathrm{SM}_{8}$, with initial guess $x_{0}=0.0$, will diverge. Similarly, $\mathrm{KM}_{4}, \mathrm{CM}_{4}^{1}, \mathrm{CM}_{4}^{2}, \mathrm{LW}_{8}$ (for $\alpha=0$ and $\beta=$ 0 ), $\mathrm{TM}_{8}, \mathrm{SS}_{8}\left(\right.$ for $\alpha=1$ ), $\mathrm{KW}_{8}$ (for $\alpha=3$ ), and $\mathrm{SM}_{8}$ with initial guess $x_{0}=0.2$ will diverge. However, newly proposed families of methods, namely, (22), (23), (32), and (33), do not exhibit this type of behavior.

\section{Attractor Basins in the Complex Plane}

We here investigate the comparison of the attained simple root finders in the complex plane using basins of attraction. It is known that the corresponding fractal of an iterative root-finding method is a boundary set in the complex plane, which is characterized by the iterative method applied to a fixed polynomial $p(z) \in \mathbb{C}$; see, for example, [16, 17]. The aim herein is to use basin of attraction as another way for comparing the iteration algorithms.

From the dynamical point of view, we consider a rectangle $D=[-3,3] \times[-3,3] \in \mathbb{C}$ with a $400 \times 400$ grid, and we assign a color to each point $z_{0} \in D$ according to the simple root at which the corresponding iterative method starting from $z_{0}$ converges, and we mark the point as black if the method does not converge. In this section, we consider the stopping criterion for convergence to be less than $10^{-4}$ wherein the maximum number of full cycles for each method is considered to be 200. In this way, we distinguish the attraction basins by their colors for different methods.

Test Problem 1. Let $p_{1}(z)=\left(z^{4}-1\right)$, having simple zeros $\{-1,-i, i, 1\}$. It is straight forward to see from Figures 1 and 2 that our method $\mathrm{MOM}_{4}$ converges to the required roots even though the derivative of function becomes zero or very small in the vicinity of required roots and contains lesser number of divergent points in comparison to the methods $\mathrm{CM}_{4}^{1}, \mathrm{KM}_{4}, \mathrm{CM}_{4}^{2}$, and $\mathrm{OM}_{4}$. Further, our method $\mathrm{MKM}_{4}$ has also performed better as compared to other methods, namely, $\mathrm{CM}_{4}^{1}, \mathrm{KM}_{4}$, and $\mathrm{CM}_{4}^{2}$.

Test Problem 2. Let $p_{2}(z)=\left(z^{6}+2 z-1\right)$, having simple zeros $\{-1.22981,-0.442247-1.11016 i,-0.442247+$ $1.11016 i, 0.492836,0.810735-0.70574 i, 0.810735+0.70574 i\}$. It is straight forward to see from Figures 3 and 4 that our method $\mathrm{MOM}_{4}$ performed better as compared to the other methods $\mathrm{CM}_{4}^{1}, \mathrm{KM}_{4}$, and $\mathrm{CM}_{4}^{2}$ and have almost the same basin of attraction of $\mathrm{OM}_{4}$. Further, our method $\mathrm{MKM}_{4}$ has also same basins of attraction as other methods, namely, $\mathrm{CM}_{4}^{1}$, $\mathrm{KM}_{4}$, and $\mathrm{CM}_{4}^{2}$.

Test Problem 3. Let $p_{3}(z)=\left(z^{8}+z\right)$, having simple zeros $\{-1,-0.62349-0.781831 i,-0.62349+0.781831 i$, $0,0.222521-0.974928 i, 0.222521+0.974928 i, 0.900969-$ $0.433884 i, 0.900969+0.433884 i\}$. It is straight forward to see from Figures 5 and 6 that our method $\mathrm{MOM}_{4}$ performed better as compared to the other methods $\mathrm{CM}_{4}^{1}, \mathrm{KM}_{4}$, and 
TABle 1

\begin{tabular}{|c|c|c|c|c|c|c|c|c|}
\hline$f(x)$ & $x_{0}$ & $\mathrm{JM}_{4}$ & $\mathrm{KM}_{4}$ & $\mathrm{MKM}_{4}$ & $\mathrm{CM}_{4}^{1}$ & $\mathrm{CM}_{4}^{2}$ & $\mathrm{OM}_{4}$ & $\mathrm{MOM}_{4}$ \\
\hline \multicolumn{9}{|c|}{ Comparison of different optimal fourth-order methods with the same total number of functional evaluations $(\mathrm{TNFE}=12)$} \\
\hline \multirow{2}{*}{$f_{1}(x)$} & -1.51 & $\mathrm{C}$ & $\mathrm{C}$ & $1.72 e-84$ & $\mathrm{C}$ & $\mathrm{C}$ & $\mathrm{C}$ & $8.91 e-81$ \\
\hline & -1.51 & $\mathrm{C}$ & $\mathrm{C}$ & $1.72 e-84$ & $\mathrm{C}$ & $\mathrm{C}$ & $\mathrm{C}$ & $8.91 e-81$ \\
\hline \multicolumn{9}{|c|}{ Comparison of different optimal fourth-order methods with respect to number of iterations } \\
\hline \multirow{2}{*}{$f_{1}(x)$} & -1.51 & $\mathrm{C}$ & $\mathrm{C}$ & 5 & $\mathrm{C}$ & $\mathrm{C}$ & $\mathrm{C}$ & 5 \\
\hline & -1.51 & $\mathrm{C}$ & $\mathrm{C}$ & 5 & $\mathrm{C}$ & $\mathrm{C}$ & $\mathrm{C}$ & 5 \\
\hline
\end{tabular}

C stands for converge to undesired root.

TABLE 2

\begin{tabular}{|c|c|c|c|c|c|c|c|c|}
\hline$f(x)$ & $x_{0}$ & $\begin{array}{c}\mathrm{LW}_{8} \\
(\alpha=0, \beta=0)\end{array}$ & $\mathrm{TM}_{8}$ & $\begin{array}{c}\mathrm{SS}_{8} \\
(\alpha=1)\end{array}$ & $\begin{array}{c}\mathrm{KW}_{8} \\
(\alpha=3)\end{array}$ & $\mathrm{SM}_{8}$ & $\begin{array}{c}\mathrm{MKM}_{8} \\
\left(\left|\lambda_{1}\right|=\frac{1}{2}\right)\end{array}$ & $\begin{array}{c}\mathrm{MOM}_{8} \\
\left(\left|\lambda_{1}\right|=\frac{1}{2}\right)\end{array}$ \\
\hline \multicolumn{9}{|c|}{ Comparison of different optimal eight-order methods with the same total number of functional evaluations $(\mathrm{TNFE}=12)$} \\
\hline \multirow{2}{*}{$f_{1}(x)$} & -1.51 & C & $\mathrm{C}$ & C & C & $\mathrm{C}$ & $4.05 e-258$ & $1.52 e-262$ \\
\hline & -1.51 & $\mathrm{C}$ & $\mathrm{C}$ & $\mathrm{C}$ & C & $\mathrm{C}$ & $4.05 e-258$ & $1.52 e-262$ \\
\hline \multicolumn{9}{|c|}{ Comparison of different optimal eight-order methods with respect to number of iterations } \\
\hline \multirow{2}{*}{$f_{1}(x)$} & -1.51 & C & $\mathrm{C}$ & C & C & $\mathrm{C}$ & 4 & 4 \\
\hline & -1.51 & $\mathrm{C}$ & $\mathrm{C}$ & $\mathrm{C}$ & $\mathrm{C}$ & $\mathrm{C}$ & 4 & 4 \\
\hline
\end{tabular}

TABle 3

\begin{tabular}{|c|c|c|c|c|c|c|c|c|}
\hline$f(x)$ & $x_{0}$ & $\mathrm{JM}_{4}$ & $\mathrm{KM}_{4}$ & $\mathrm{MKM}_{4}$ & $\mathrm{CM}_{4}^{1}$ & $\mathrm{CM}_{4}^{2}$ & $\mathrm{OM}_{4}$ & $\mathrm{MOM}_{4}$ \\
\hline \multicolumn{9}{|c|}{ Comparison of different optimal fourth-order methods with the same total number of functional evaluations $($ TNFE $=12)$} \\
\hline \multirow{4}{*}{$f_{2}(x)$} & 1.4 & $\mathrm{C}$ & $\mathrm{C}$ & $2.02 e-216$ & $9.76 e-93$ & $\mathrm{C}$ & $\mathrm{C}$ & $3.14 e-212$ \\
\hline & 1.5 & $\mathrm{C}$ & $\mathrm{C}$ & $1.31 e-147$ & C & $\mathrm{C}$ & $\mathrm{C}$ & $1.90 e-145$ \\
\hline & 2.5 & $1.24 e-188$ & $2.33 e-177$ & $1.62 e-203$ & $1.12 e-131$ & $1.17 e-104$ & $6.84 e-187$ & $1.45 e-141$ \\
\hline & 4.0 & $2.20 e-140$ & $7.87 e-122$ & $5.98 e-232$ & $6.43 e-80$ & $1.51 e-40$ & $6.36 e-140$ & $3.62 e-163$ \\
\hline \multicolumn{9}{|c|}{ Comparison of different optimal fourth-order methods with respect to number of iterations } \\
\hline \multirow{4}{*}{$f_{2}(x)$} & 1.4 & C & C & 4 & 5 & C & C & 4 \\
\hline & 1.5 & $\mathrm{C}$ & $\mathrm{C}$ & 4 & $\mathrm{C}$ & $\mathrm{C}$ & $\mathrm{C}$ & 4 \\
\hline & 2.5 & 4 & 4 & 4 & 5 & 5 & 4 & 4 \\
\hline & 4.0 & 4 & 5 & 4 & 5 & 5 & 4 & 4 \\
\hline
\end{tabular}

TABLE 4

\begin{tabular}{|c|c|c|c|c|c|c|c|c|}
\hline$f(x)$ & $x_{0}$ & $\begin{array}{c}\mathrm{LW}_{8} \\
(\alpha=0, \beta=0)\end{array}$ & $\mathrm{TM}_{8}$ & $\begin{array}{c}\mathrm{SS}_{8} \\
(\alpha=1)\end{array}$ & $\begin{array}{c}\mathrm{KW}_{8} \\
(\alpha=3)\end{array}$ & $\mathrm{SM}_{8}$ & $\begin{array}{c}\mathrm{MKM}_{8} \\
\left(\left|\lambda_{1}\right|=\frac{1}{2}\right)\end{array}$ & $\begin{array}{c}\mathrm{MOM}_{8} \\
\left(\left|\lambda_{1}\right|=\frac{1}{2}\right)\end{array}$ \\
\hline
\end{tabular}

Comparison of different optimal eight-order methods with the same total number of functional evaluations $($ TNFE $=12)$

\begin{tabular}{ccccccccc} 
& 1.4 & $\mathrm{C}$ & $\mathrm{C}$ & $\mathrm{C}$ & $\mathrm{C}$ & $\mathrm{C}$ & $6.04 e-449$ & $6.45 e-445$ \\
$f_{2}(x)$ & 1.5 & $8.22 e-48$ & $2.29 e-59$ & $\mathrm{C}$ & $\mathrm{C}$ & $\mathrm{C}$ & $9.54 e-301$ & $9.53 e-299$ \\
& 2.5 & $6.73 e-290$ & $6.37 e-277$ & $1.13 e-379$ & $1.15 e-234$ & $1.22 e-296$ & $2.21 e-412$ & $1.46 e-374$ \\
& 4.0 & $5.05 e-172$ & $1.68 e-154$ & $1.94 e-247$ & $1.32 e-305$ & $1.21 e-189$ & $8.07 e-433$ & $4.60 e-359$ \\
\hline
\end{tabular}

\begin{tabular}{ccccccccc}
\hline \multicolumn{8}{c}{} & \multicolumn{7}{c}{ Comparison of different optimal eight-order methods with respect to number of iterations } \\
& 1.4 & $\mathrm{C}$ & $\mathrm{C}$ & $\mathrm{C}$ & $\mathrm{C}$ & $\mathrm{C}$ & 3 & 3 \\
$f_{2}(x)$ & 4 & 4 & $\mathrm{C}$ & $\mathrm{C}$ & $\mathrm{C}$ & 3 & 3 \\
& 1.5 & 3 & 3 & 3 & 3 & 3 & 3 \\
& 2.5 & 4 & 4 & 4 & 4 & 4 & 3 \\
\hline
\end{tabular}


TABLE 5

\begin{tabular}{ccccccccc}
\hline$f(x)$ & $x_{0}$ & $\mathrm{JM}_{4}$ & $\mathrm{KM}_{4}$ & $\mathrm{MKM}_{4}$ & $\mathrm{CM}_{4}^{1}$ & $\mathrm{CM}_{4}^{2}$ & $\mathrm{OM}_{4}$ & $\mathrm{MOM}_{4}$ \\
\hline \multicolumn{7}{c}{ Comparison of different optimal fourth-order methods with the same total number of functional evaluations (TNFE = 12) } \\
$f_{3}(x)$ & -0.8 & $3.04 e-84$ & $1.74 e-52$ & $4.00 e-91$ & $5.21 e-61$ & $1.45 e-74$ & $1.83 e-85$ & $1.41 e-104$ \\
& 0.9 & $1.83 e-2$ & $\mathrm{D}$ & $5.10 e-5$ & $1.71 e+3475$ & $\mathrm{C}$ & $1.50 e-2$ & $1.10 e-46$ \\
& 1.0 & $\mathrm{~F}$ & $\mathrm{~F}$ & $2.48 e-1$ & $\mathrm{~F}$ & $\mathrm{~F}$ & $\mathrm{~F}$ & $1.57 e-35$ \\
\hline \multicolumn{7}{c}{ Comparison of different optimal fourth-order methods with respect to number of iterations } \\
$f_{3}(x)$ & -0.8 & 5 & 5 & 5 & 5 & 5 & 5 & 5 \\
& 0.9 & 8 & $\mathrm{D}$ & 7 & 4048 & $\mathrm{C}$ & 5 \\
\hline
\end{tabular}

$\mathrm{D}$ stands for diverge. F stands for failure.

TAble 6

\begin{tabular}{|c|c|c|c|c|c|c|c|c|}
\hline$f(x)$ & $x_{0}$ & $\begin{array}{c}\mathrm{LW}_{8} \\
(\alpha=0, \beta=0)\end{array}$ & $\mathrm{TM}_{8}$ & $\begin{array}{c}\mathrm{SS}_{8} \\
(\alpha=1)\end{array}$ & $\begin{array}{c}\mathrm{KW}_{8} \\
(\alpha=3)\end{array}$ & $\mathrm{SM}_{8}$ & $\begin{array}{c}\mathrm{MKM}_{8} \\
\left(\left|\lambda_{1}\right|=\frac{1}{2}\right)\end{array}$ & $\begin{array}{c}\mathrm{MOM}_{8} \\
\left(\left|\lambda_{1}\right|=\frac{1}{2}\right)\end{array}$ \\
\hline \multicolumn{9}{|c|}{ Comparison of different optimal eight-order methods with the same total number of functional evaluations $(\mathrm{TNFE}=12)$} \\
\hline \multirow{3}{*}{$f_{3}(x)$} & -0.8 & $5.15 e-120$ & $3.08 e-82$ & $2.64 e-146$ & $2.17 e-156$ & $9.58 e-124$ & $1.21 e-162$ & $2.48 e-178$ \\
\hline & 0.9 & $\mathrm{D}$ & $\mathrm{D}$ & $\mathrm{C}$ & C & D & $4.23 e-7$ & $3.34 e-76$ \\
\hline & 1.0 & $\mathrm{~F}$ & $\mathrm{~F}$ & $\mathrm{~F}$ & $\mathrm{~F}$ & $\mathrm{~F}$ & $1.56 e-1$ & $2.10 e-55$ \\
\hline
\end{tabular}

Comparison of different optimal eight-order methods with respect to number of iterations

\begin{tabular}{ccccccccc} 
& -0.8 & 4 & 4 & 4 & 4 & 4 & 4 & 4 \\
$f_{3}(x)$ & 0.9 & $\mathrm{D}$ & $\mathrm{D}$ & $\mathrm{C}$ & $\mathrm{C}$ & $\mathrm{D}$ & 5 & 4 \\
& 1.0 & $\mathrm{~F}$ & $\mathrm{~F}$ & $\mathrm{~F}$ & $\mathrm{~F}$ & $\mathrm{~F}$ & 6 & 4 \\
\hline
\end{tabular}

TABle 7

\begin{tabular}{|c|c|c|c|c|c|c|c|c|}
\hline$f(x)$ & $x_{0}$ & $\mathrm{JM}_{4}$ & $\mathrm{KM}_{4}$ & $\mathrm{MKM}_{4}$ & $\mathrm{CM}_{4}^{1}$ & $\mathrm{CM}_{4}^{2}$ & $\mathrm{OM}_{4}$ & $\mathrm{MOM}_{4}$ \\
\hline \multicolumn{9}{|c|}{ Comparison of different optimal fourth-order methods with the same total number of functional evaluations $($ TNFE $=10)$} \\
\hline \multirow{4}{*}{$f_{4}(x)$} & -1.9 & $1.34 e-51$ & $4.52 e-20$ & $4.68 e-28$ & $2.65 e-21$ & $8.80 e-23$ & $4.94 e-59$ & $5.06 e-59$ \\
\hline & -0.8 & $1.64 e-139$ & $8.21 e-15$ & $2.97 e-106$ & $2.08 e-43$ & $6.54 e-50$ & $3.08 e-176$ & $1.19 e-235$ \\
\hline & 0.0 & $3.24 e+4$ & D & $8.07 e-2$ & D & D & $2.80 e+4$ & $7.44 e-98$ \\
\hline & 0.2 & $1.05 e+426$ & $\mathrm{D}$ & $1.19 e+5$ & $\mathrm{D}$ & $\mathrm{D}$ & $9.32 e+425$ & $2.85 e-71$ \\
\hline \multicolumn{9}{|c|}{ Comparison of different optimal fourth-order methods with respect to number of iterations } \\
\hline \multirow{4}{*}{$f_{4}(x)$} & -1.9 & 5 & 6 & 6 & 6 & 6 & 5 & 5 \\
\hline & -0.8 & 4 & 6 & 5 & 5 & 5 & 4 & 4 \\
\hline & 0.0 & 12 & $\mathrm{D}$ & 7 & $\mathrm{D}$ & $\mathrm{D}$ & 12 & 5 \\
\hline & 0.2 & 425 & $\mathrm{D}$ & 14 & $\mathrm{D}$ & $\mathrm{D}$ & 417 & 5 \\
\hline
\end{tabular}

TABle 8

\begin{tabular}{ccccccc}
\hline & & $\mathrm{LW}_{8}$ & $\mathrm{TS}_{8}$ & $\mathrm{KW}_{8}$ & $\mathrm{MKM}_{8}$ & $\mathrm{MOM}_{8}$ \\
& $x_{0}(x) \quad(\alpha=0, \beta=0)$ & $\mathrm{TM}_{8}$ & $(\alpha=1)$ & $(\alpha=3)$ & $\mathrm{SM}_{8}$ & $\left(\left|\lambda_{1}\right|=\frac{1}{2}\right) \quad\left(\left|\lambda_{1}\right|=\frac{1}{2}\right)$ \\
\hline
\end{tabular}

Comparison of different optimal eight-order methods with the same total number of functional evaluations $($ TNFE $=12)$

\begin{tabular}{ccccccccc} 
& -1.9 & $2.37 e-71$ & $3.77 e-29$ & $4.23 e-97$ & $3.58 e-96$ & $1.13 e-63$ & $7.56 e-43$ & $2.04 e-63$ \\
$f_{4}(x)$ & -0.8 & $5.22 e-229$ & $\mathrm{D}$ & $1.38 e-318$ & $4.00 e-353$ & $3.79 e-123$ & $3.06 e-194$ & $3.59 e-339$ \\
& 0.0 & $\mathrm{D}$ & $\mathrm{D}$ & $\mathrm{D}$ & $\mathrm{D}$ & $\mathrm{D}$ & $1.76 e-5$ & $6.59 e-121$ \\
& 0.2 & $\mathrm{D}$ & $\mathrm{D}$ & $\mathrm{D}$ & $\mathrm{D}$ & $\mathrm{D}$ & $1.04 e+00$ & $4.52 e-83$ \\
\hline
\end{tabular}

Comparison of different optimal eight-order methods with respect to number of iterations

\begin{tabular}{ccccccccc} 
& -1.9 & 4 & 5 & 4 & 4 & 4 & 4 & 4 \\
$f_{4}(x)$ & -0.8 & 4 & $\mathrm{D}$ & 3 & 3 & 4 & 4 & 3 \\
& 0.0 & & $\mathrm{D}$ & $\mathrm{D}$ & $\mathrm{D}$ & $\mathrm{D}$ & 5 & 4 \\
& 0.2 & $\mathrm{D}$ & $\mathrm{D}$ & $\mathrm{D}$ & $\mathrm{D}$ & $\mathrm{D}$ & 8 & 4 \\
\hline
\end{tabular}




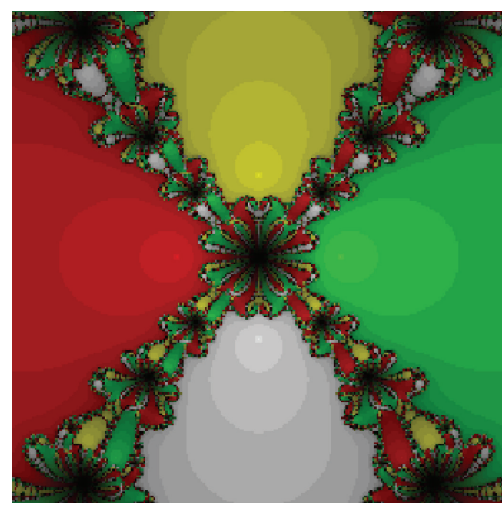

(a)

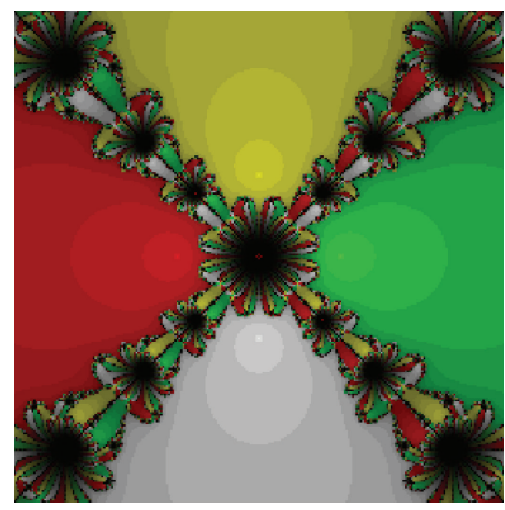

(b)

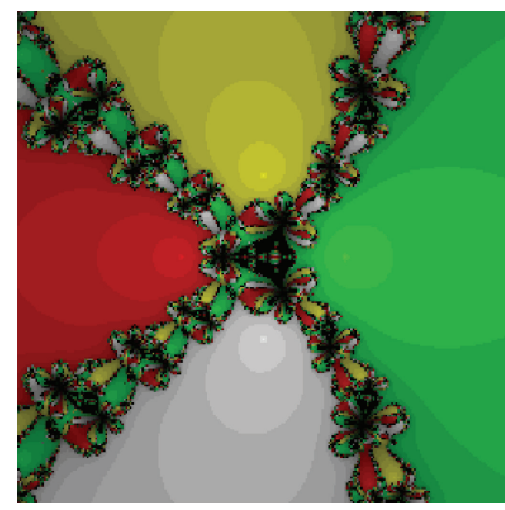

(c)

FIgURE 1: The basins of attraction for $\mathrm{CM}_{4}^{1}$ (a), $\mathrm{KM}_{4}$ (b), and $\mathrm{MKM}_{4}$ (c) in problem 1.

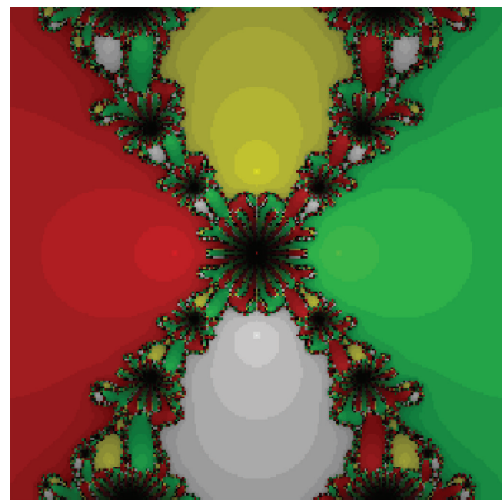

(a)

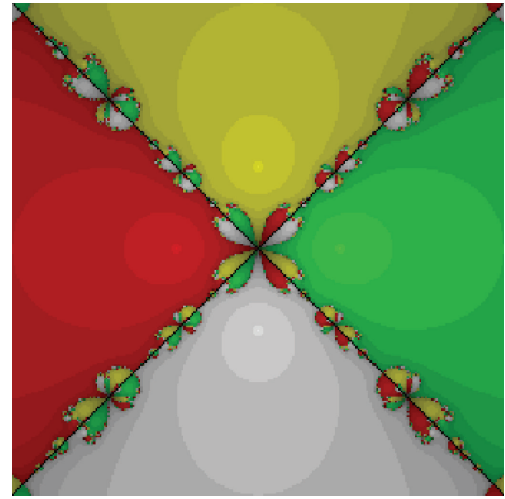

(b)

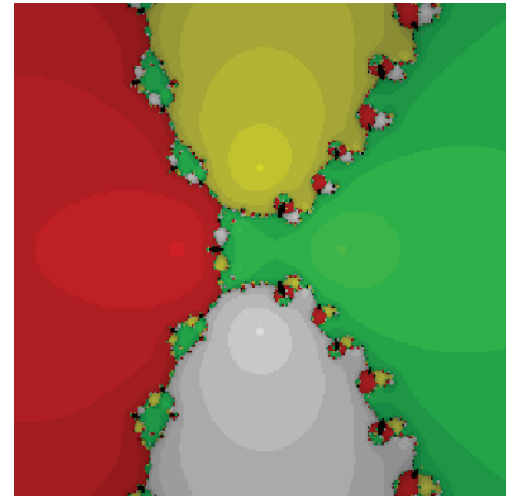

(c)

FIGURE 2: The basins of attraction for $\mathrm{CM}_{4}^{2}(\mathrm{a}), \mathrm{OM}_{4}(\mathrm{~b})$, and $\mathrm{MOM}_{4}(\mathrm{c})$ in problem 1.

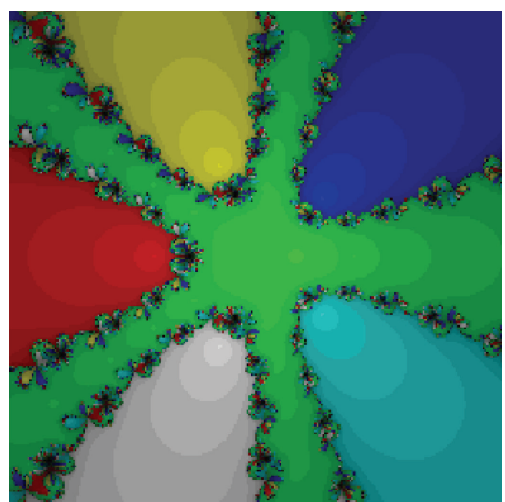

(a)

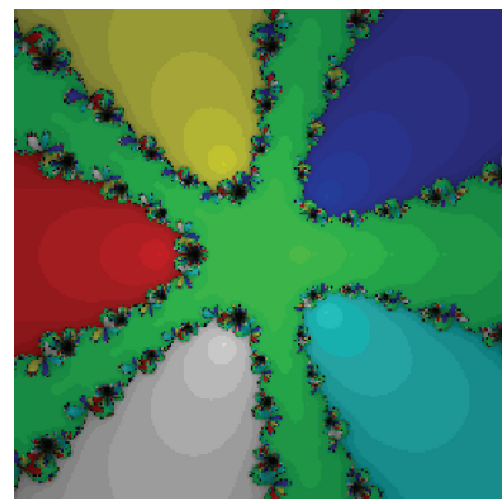

(b)

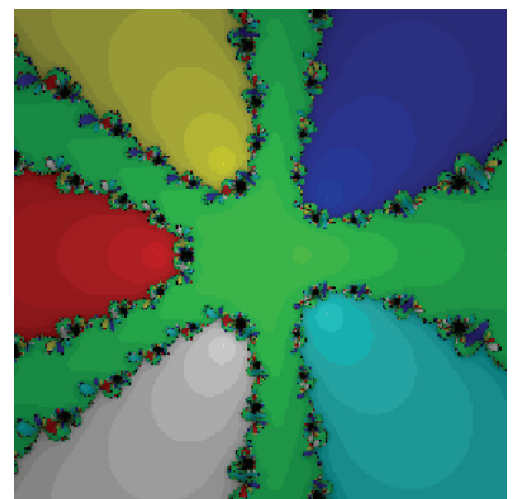

(c)

FIgURE 3: The basins of attraction for $\mathrm{CM}_{4}^{1}(\mathrm{a}), \mathrm{KM}_{4}(\mathrm{~b})$, and $\mathrm{MKM}_{4}(\mathrm{c})$ in problem 2.

$\mathrm{CM}_{4}^{2}$. Also note that our method $\mathrm{MKM}_{4}$ has less chaotic behavior than other methods, namely, $\mathrm{CM}_{4}^{1}$ and $\mathrm{CM}_{4}^{2}$.

\section{Conclusions}

In this paper, we have developed optimal and globally convergent fourth-order families of Jarratt's, Ostrowski's, and King's method for the first time, which will converge to the required root even though the guess is far away from zero or the derivative is small in the vicinity of required root. Further, we have also introduced new three-point optimal eighth-order families of King's family, in which $f^{\prime}(x)=0$ is permitted. Ostrowski's method and King's family are obtained as the special cases of our proposed schemes. Numerical results 


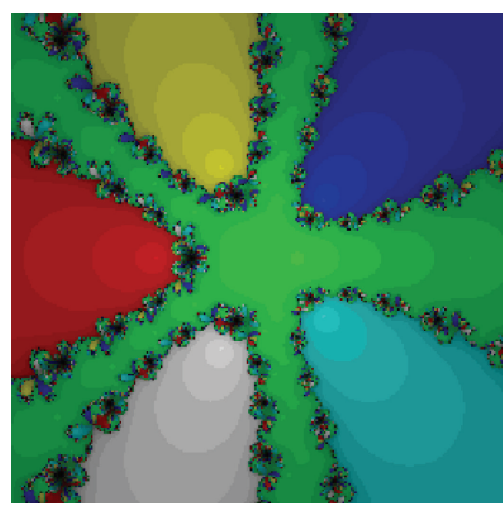

(a)

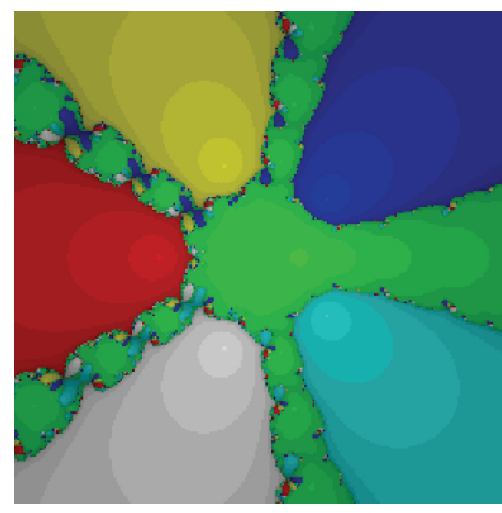

(b)

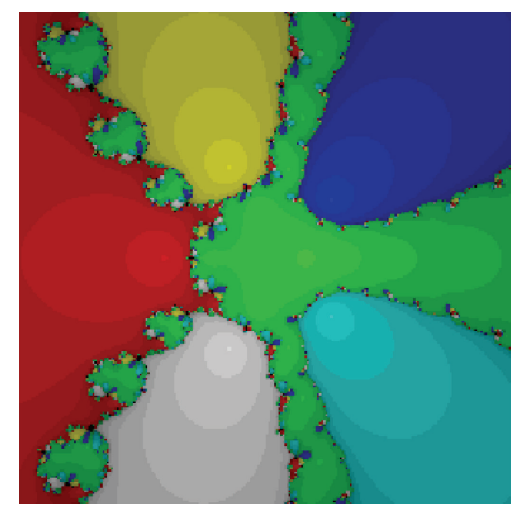

(c)

FIGURE 4: The basins of attraction for $\mathrm{CM}_{4}^{2}$ (a), $\mathrm{OM}_{4}$ (b), and $\mathrm{MOM}_{4}$ (c) in problem 2.

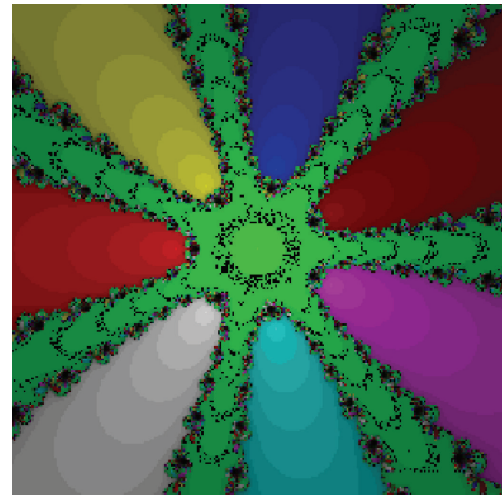

(a)

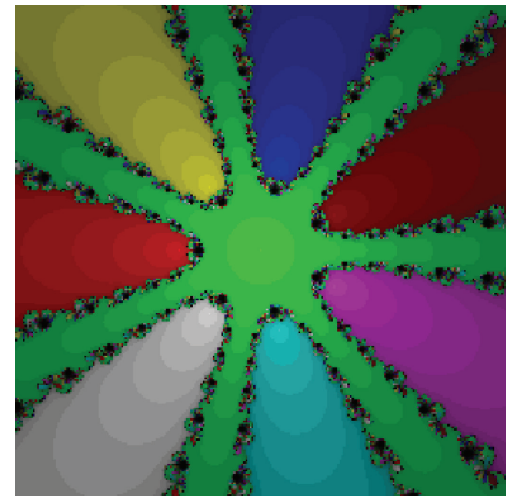

(b)

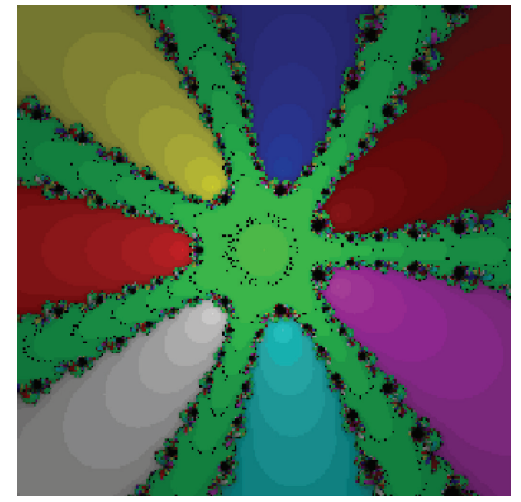

(c)

FIGURE 5: The basins of attraction for $\mathrm{CM}_{4}^{1}(\mathrm{a}), \mathrm{KM}_{4}(\mathrm{~b})$, and $\mathrm{MKM}_{4}$ (c) in problem 3.

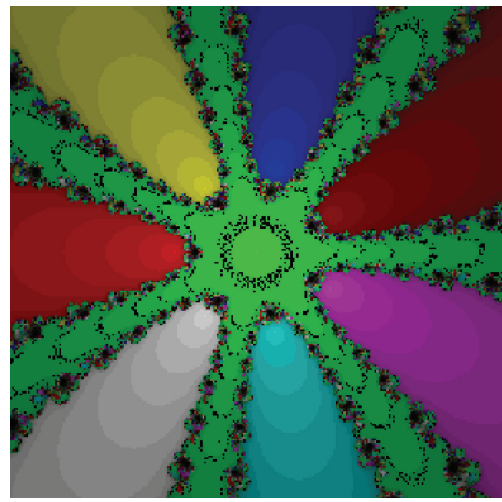

(a)

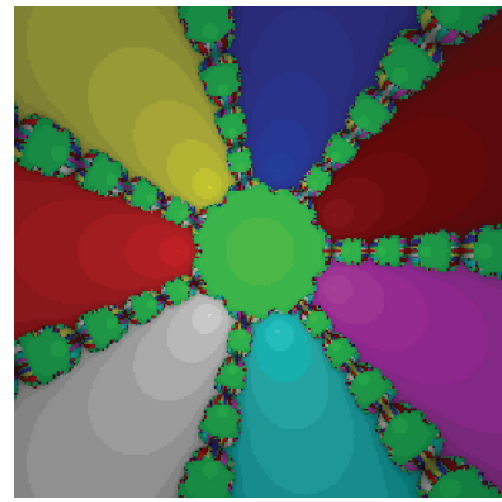

(b)

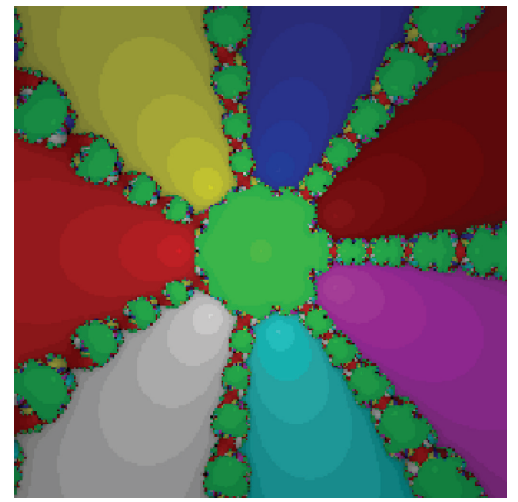

(c)

FIgURE 6: The basins of attraction for $\mathrm{CM}_{4}^{2}(\mathrm{a}), \mathrm{OM}_{4}$ (b), and $\mathrm{MOM}_{4}$ (c) in problem 3.

displayed in the above mentioned tables show the consistent convergence behavior of newly proposed methods. All the proposed methods considered here are found to be more effective and comparable to the classical Jarratt's method, Ostrowski's method, King's method, and recently developed four and eight-order methods, respectively. Furthermore, it is also investigated that our modified families have better region of stability, when $\left|\lambda_{1}\right|$ is very small. The dynamic study of the methods also supports this theoretical aspect. In similar ways, one can easily check the dynamical behavior of eight-order methods.

\section{Conflict of Interests}

The author declares that there is no conflict of interests regarding the publication of this paper. 


\section{References}

[1] S. Kumar, V. Kanwar, S. K. Tomar, and S. Singh, "Geometrically constructed families of Newton's method for unconstrained optimization and nonlinear equations," International Journal of Mathematics and Mathematical Sciences, vol. 2011, Article ID 972537, 9 pages, 2011.

[2] M. S. Petković, B. Neta, L. D. Petković, and J. Dzunić, Multipoint Methods for Solving Nonlinear Equations, Elsevier, 2012.

[3] R. F. King, "A family of fourth order methods for nonlinear equations," SIAM Journal on Numerical Analysis, vol. 10, pp. 876-879, 1973.

[4] A. M. Ostrowski, Solutions of Equations and System of Equations, Academic Press, New York, NY, USA, 1960.

[5] V. Kanwar, R. Behl, and K. K. Sharma, "Simply constructed family of a Ostrowski's method with optimal order of convergence," Computers \& Mathematics with Applications, vol. 62, no. 11, pp. 4021-4027, 2011.

[6] V. Kanwar and S. K. Tomar, "Exponentially fitted variants of Newton's method with quadratic and cubic convergence," International Journal of Computer Mathematics, vol. 86, no. 9, pp. 1603-1611, 2009.

[7] P. Jarratt, "Some efficient fourth order multipoint methods for solving equations," BIT Numerical Mathematics, vol. 9, pp. 119$124,1969$.

[8] H. T. Kung and J. F. Traub, "Optimal order of one-point and multipoint iteration," Journal of the Association for Computing Machinery, vol. 21, pp. 643-651, 1974.

[9] C. Chun, "A family of composite fourth-order iterative methods for solving nonlinear equations," Applied Mathematics and Computation, vol. 187, no. 2, pp. 951-956, 2007.

[10] F. Soleymani, S. Karimi Vanani, M. Khan, and M. Sharifi, "Some modifications of King's family with optimal eighth order of convergence," Mathematical and Computer Modelling, vol. 55, no. 3-4, pp. 1373-1380, 2012.

[11] J. F. Traub, Iterative Methods for the Solution of Equations, Prentice-Hall, Englewood Cliffs, NJ, USA, 1964.

[12] J. Kou and X. Wang, "Some improvements of Ostrowski's method," Applied Mathematics Letters, vol. 23, no. 1, pp. 92-96, 2010.

[13] J. R. Sharma and R. Sharma, "A new family of modified Ostrowski's methods with accelerated eighth order convergence," Numerical Algorithms, vol. 54, no. 4, pp. 445-458, 2010.

[14] L. Liu and X. Wang, "Eighth-order methods with high efficiency index for solving nonlinear equations," Applied Mathematics and Computation, vol. 215, no. 9, pp. 3449-3454, 2010.

[15] R. Thukral, "A new eighth-order iterative method for solving nonlinear equations," Applied Mathematics and Computation, vol. 217, no. 1, pp. 222-229, 2010.

[16] M. Scott, B. Neta, and C. Chun, "Basin attractors for various methods," Applied Mathematics and Computation, vol. 218, no. 6, pp. 2584-2599, 2011.

[17] B. Neta, M. Scott, and C. Chun, "Basins of attraction for several methods to find simple roots of nonlinear equations," Applied Mathematics and Computation, vol. 218, no. 21, pp. 10548-10556, 2012. 


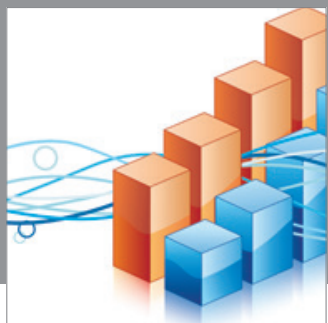

Advances in

Operations Research

mansans

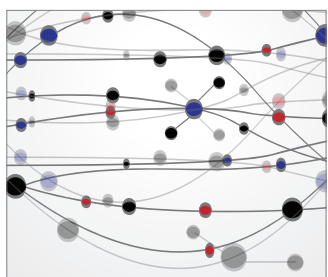

The Scientific World Journal
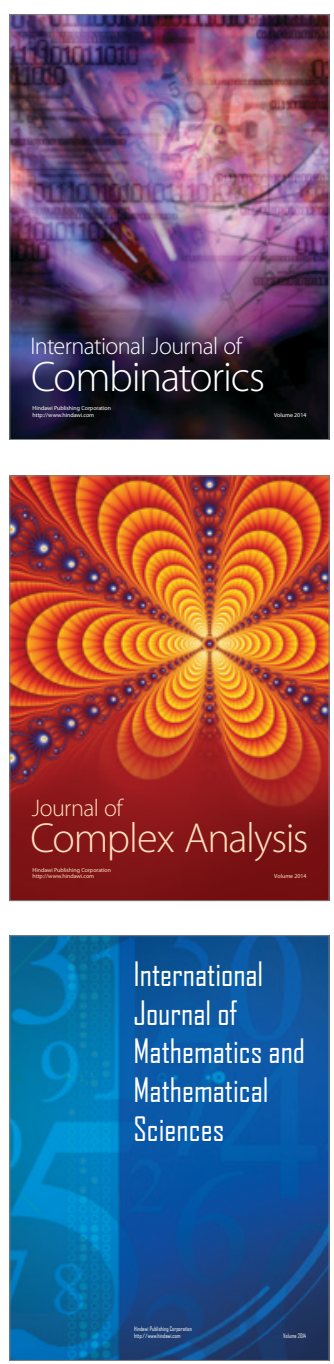
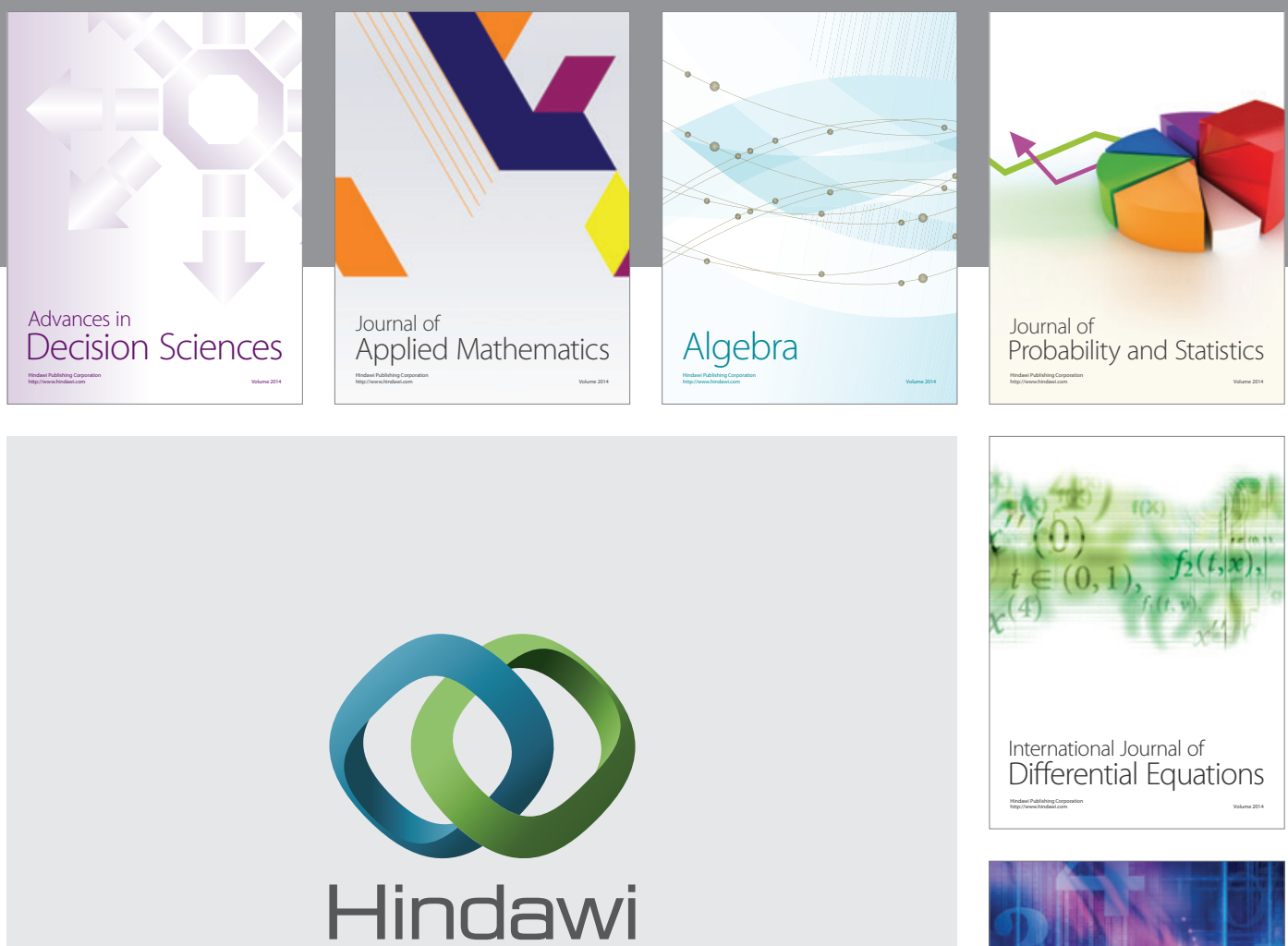

Submit your manuscripts at http://www.hindawi.com
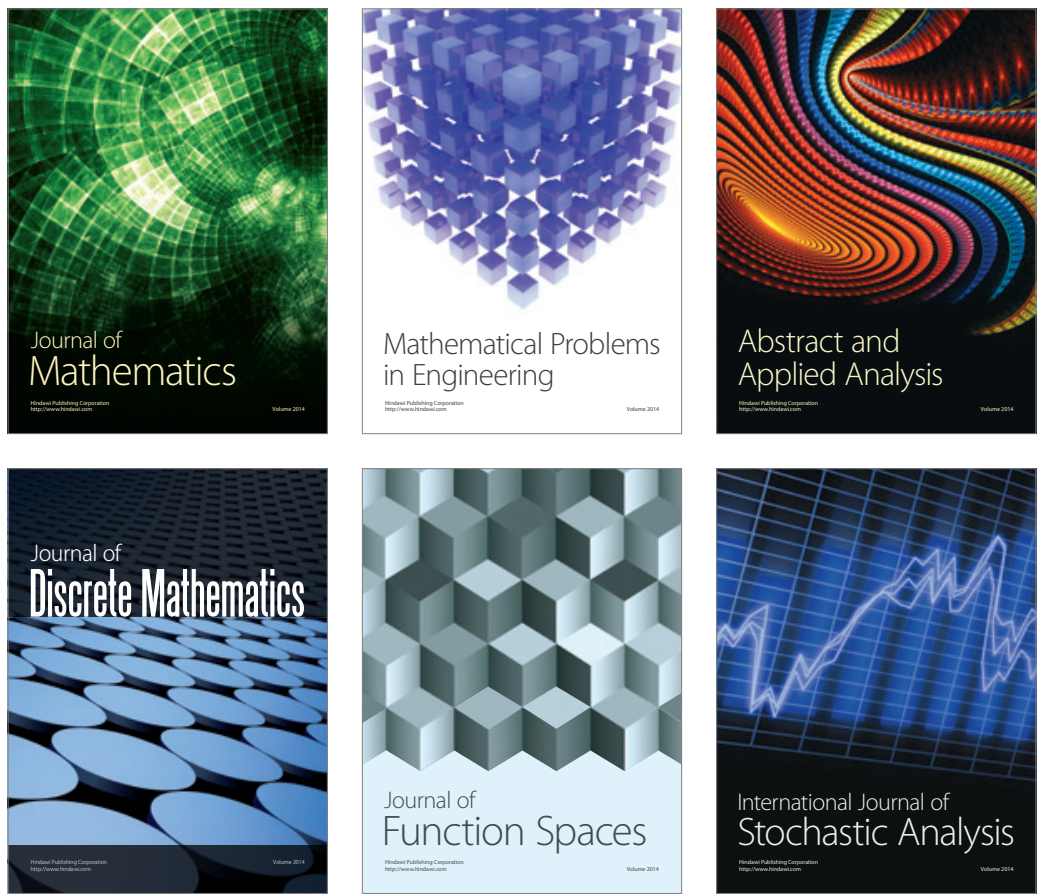

Journal of

Function Spaces

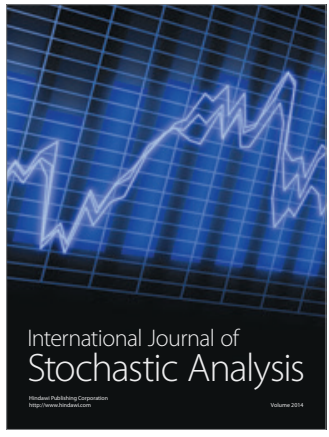

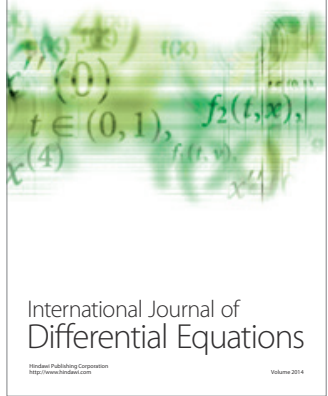
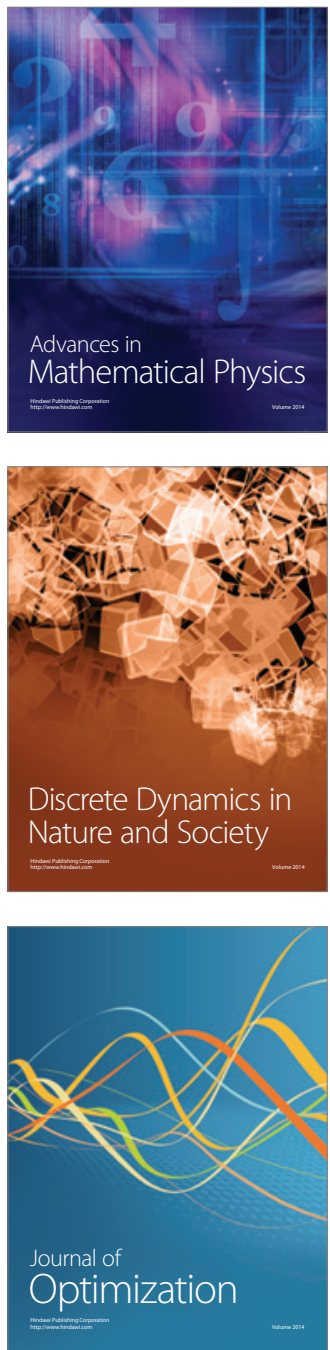